Fecha de recepción: febrero 2017 Fecha de aceptación: agosto 2017 Versión final: septiembre 2018

\section{Design, comportamento e juventude: gerações Baby Boomer, X e Y}

Anderson Antonio Horta *

Resumen: En el intento de comprender las relaciones entre bienes de consumo y comportamiento, así como la actuación del diseño en ese complejo constructo, se hace necesario percibir el contexto en que ellas ocurren y cuáles son las influencias y tendencias comportamentales dentro de ese campo, una vez que se transforma en natural pensamos que estos factores se transforman constantemente, adaptándose a los cambios ocurridos a lo largo del tiempo.

El presente trabajo está dedicado al estudio de las relaciones entre la idea de la juventud y las referencias, así como también las propuestas de diseño en la contemporaneidad, que vienen reflejando cambios importantes del medio social. Tales alteraciones abarcan tanto a jóvenes adultos, personas de mediana edad y ancianos, generando comportamientos de consumo de bienes y experiencias pautadas por las generaciones.

Palabras clave: propuestas de diseño, juventud, valor, consumo, tiempo.

[Resúmenes en inglés y portugués en la página 67]

${ }^{(*)}$ Designer, pesquisador e professor do curso de Design da Universidade do Estado de Minas Gerais - UEMG e Centro Universitário Uni BH, Brasil.

\title{
Introdução
}

É notório que o Design está sempre atrelado a seu contexto de produção e absorção, tratando, assim, de aspectos culturais, comportamentais e momentos históricos, funcionando como espelho social.

Verganti (2012) retrata o design como sendo uma proposta que seu criador apresenta ao mundo. Essa visão considera o designer como pessoa, antes de mais nada, isto é, como tendo seus próprios referenciais e repertório, pertencente ao contexto em que vive, sofrendo as influências culturais presentes em seu tempo e local. E, segundo ele, é baseado nesse repertório que se criam e desenvolvem os produtos a serem oferecidos ao público. Portanto, o autor contextualiza o designer e atribui a ele a possibilidade de manejo do seu repertório, naturalmente muito parecido com os demais indivíduos de seu tempo que sofrem as mesmas influências e vivem no mesmo meio, para formular suas propostas em forma de produtos a serem consumidos. Essa ideia reforça a percepção do design como linguagem e 
demonstra ainda que a comunicação, em questão, dá-se por manuseio de signos por parte do proponente, designer, que devem ser inteligíveis para o receptor, o consumidor, a fim de ser efetivada. Portanto, podemos ver o designer como manipulador de signos para geração de significados a serem interpretados pelo consumidor, como aponta Sudjic (2010). O consumidor, por sua vez, vislumbra nos bens de consumo possibilidades de interação que vão além da simples necessidade de uso prático. As relações entre pessoas e objetos ou serviços, bem como suas escolhas de consumo, em um meio com inúmeras possibilidades em oferta, com características funcionais semelhantes ou mesmo idênticas, mas imbuídas de significados distintos, se tornam cada vez mais complexas com o desenvolvimento social e o passar dos tempos. "[...] pessoas não compram produtos, mas, sim, significados. As pessoas usam coisas por profundas razões emocionais, psicológicas e socioculturais, tanto quanto utilitárias" (Verganti, 2012, p. 04). Podemos assim vislumbrar a intensa, diversa e complexa relação entre criação/produção de bens e seu consumo, bem como a importância do papel do design como gerador de sentido.

Tais sentidos passam por variações ao longo dos tempos, alcançando diferentes públicos em contextos distintos. Essas mesmas mudanças acompanham as gerações, cada qual com seu conjunto de características próprias, simultaneamente resultado e causa do meio em constante transformação no qual são formadas, como descrito em estudo no campo da Sociologia por Karl Mannheim, tido como fundador da abordagem moderna sobre o tema geracional, em Das Problem der Generationen (O Problema das Gerações), publicado originalmente em 1928:

[...] la conexión generacional no es, ante todo, otra cosa que una modalidad específica de posición de igualdad dentro del ámbito histórico-social, debida a la proximidad de los años de nacimiento. Si lo que es propio de la posición de las condiciones económico-sociales, por su parte, la posición generacional se puede determinar a partir de ciertos momentos vitales basados en los dados naturales de la mudanza de las generaciones- que sugieren a los individuos afectados por ellos determinadas formas de vivencia y pensamiento. (Mannheim, 1993, p. 210)

A partir desta definição feita por Mannheim (1993) podemos vislumbrar com maior clareza o próprio significado do termo geração e suas implicações, tornando possível uma melhor distinção das definições anteriores, matematizadas, que não se atentam às relações entre gerações e fatos sociais, baseando-se unicamente na cronologia para separar tais grupos (Mannheim, 1993) da definição aqui utilizada e amplamente aceita do período moderno em diante.

Faz-se necessário esclarecer as definições, recortes e nomenclaturas empregadas aqui acerca das gerações, bem como suas delimitações. São citadas, por determinação de recorte, as chamadas Geração Baby Boom ou Baby Boomers, a Geração X ou os Xers, e a Geração Y. Sendo este terceiro grupo o foco de maior atenção.

O grupo geracional dos Boomers é descrito como o dos filhos do Baby Boom, fenômeno mundial em que as taxas de natalidade sofreram aumento singular, após a Segunda Grande Guerra, indo de 1945 a, aproximadamente, 1965. (Hobsbawm, 2009) 
Já a Geração X, grupo que sucedeu os Baby Boomers, têm o nascimento de seus primeiros membros demarcado, sempre de forma aproximada, uma vez que não se considera ruptura claramente definida entre gerações, em 1966 e seu encerramento em 1982 (Bauman, 2011) e tem como uma de suas grandes marcas sociais as alterações relacionadas à transição do mundo analógico ou mecânico para o mundo digital e todas as implicações dele derivadas, que serão tratadas adiante. $\mathrm{O}$ termo Geração $\mathrm{X}$ foi utilizado para identificar o grupo em questão, a princípio, pelo escritor canadense Douglas Coupland em seu romance Generation X: Tales for an Accelerated Culture de 1991, e foi adotada no ocidente em geral, devido ao grande alcance e impacto da obra, inclusive por pesquisadores dos temas geracionais daí por diante. Neste livro a letra X é empregada com a conotação de incógnita, visão comum no contexto em que foi lançado acerca dos indivíduos que estavam se formando em um mundo tão distinto e de aceleradas mudanças em relação àquele em que as gerações anteriores se viram em sua juventude. A chamada Geração Y, delimitada, aproximadamente, entre 1983 e 2000 (Bauman, 2011), recebe esse nome porque, assim como seu próprio limite de demarcação em relação à geração imediatamente anterior, é vista como subsequente a ela, sendo a transição do mundo digital para o mundo virtual sua principal marca contextual. Assim a ordem alfabética parece lógica para sua nomenclatura, passando a se contar do X para o $\mathrm{Y}$ e, mais adiante, para a geração seguinte, a Z. As relações de consumo e, por consequência, da realização e recepção das propostas de design, ocorre de maneiras distintiva no contexto atual. Mesmo tendo grupos geracionais muito distintos convivendo no mesmo cenário, a maneira com que se comporta o consumidor é pautada por fenômenos comportamentais que alteram essa organização etária. Não se deve pensar em perfis de definição estanque, que compreendam simplesmente público jovem, adulto e idoso. No entanto, as faixas etárias e características geracionais não deixam de exercer influência nas escolhas dos indivíduos, portanto, sobre o design a eles direcionado. E é sobre esse contexto de complexos contornos que se tratará a seguir.

\section{Gerações, contexto e tempo}

Quando falamos sobre transformações sociais e de mudanças nas maneiras de consumir e de propor bens de consumo ao longo do tempo, podemos traçar um caminho histórico que torna perceptível o desenrolar dessas alterações que resultaram no cenário atual. Este, por sua vez, deve ser suficientemente abrangente para fazer perceber o todo sem perder de vista os preciosos detalhes e particularidades dessas mudanças. Uma forma que torna este desafiador feito possível é o traçado por um referencial geracional. Ainda que a princípio possa causar estranhamento pelas inúmeras particularidades apresentadas pelos indivíduos, potencialmente impossíveis de se agrupar e organizar para uma análise de grupo, vê-se características comuns passíveis de serem evidenciadas e atribuídas a grupos geracionais. Bauman (2011), ao tratar sobre as análises geracionais, afirma:

Nenhum ser humano é exatamente igual a outro -e isso se aplica tanto aos jovens quanto aos velhos. Contudo, é possível notar que, em determinadas categorias de seres humanos, algumas características ou atributos tendem 
a aparecer com maior frequência que em outras. É essa 'condensação relativa' de traços característicos que nos permite falar, em primeiro lugar, em 'categorias', sejam elas nações, classes, gêneros ou gerações. Ao fazê-lo, ignoramos temporariamente a multiplicidade de características que faz de cada um de seus integrantes uma entidade única e irrepetível, diferente de todas as outras, um ser que se destaca de todos os demais membros da 'mesma categoria'. (Bauman, 2011, p. 58)

Partindo desse princípio, podemos agrupar todos os adultos contemporâneos, salvo pessoas muito mais velhas, nascidas antes de 1945, em três gerações subsequentes: os Baby Boomers, os da geração X ou Xers e os da geração Y, como já apresentado. Cada qual fruto de seu tempo e contexto sócio-histórico-cultural. Essas três gerações foram marcadas por alterações no contexto social em torno da própria noção e motivações para o consumo, de forma distinta, marcante e consequencial.

Os anos pós-Segunda-Guerra foram vistos como tempos de mudanças positivas e de acelerado crescimento nos ditos países desenvolvidos. Os Estados Unidos continuaram seu desenvolvimento, iniciado ainda durante a Guerra e a Europa se refazia com novas perspectivas. “[...] os observadores - sobretudo, para início de conversa, os economistas - começaram a perceber que o mundo, em particular o mundo do capitalismo desenvolvido, passara por uma fase excepcional de sua história; talvez uma fase única”. (Hobsbawm, 2009, p. 253)

Essa foi a chamada Era de Ouro ou, como chamaram os franceses, Lês Trente Glorieuses (os trinta gloriosos), instaurando-se entre os anos de 1950, 60 e 70. Nesse período a industrialização batia todos os seus próprios recordes. Os produtos para consumo das massas tomavam conta das prateleiras pelo mundo e uma agitação social se fazia presente, o que causaria muitas transformações no período.

Nos Estados Unidos, com o retorno dos combatentes ao país, houve o fenômeno chamado Baby Boom, com as taxas de natalidade crescendo vertiginosamente. A população permaneceu em crescimento acelerado naquele país durante décadas, o que acarretou inúmeras mudanças mercadológicas e sociais. Podemos ressaltar o aumento da produção industrial e agrícola, para atender à nova demanda ávida por toda sorte de bens, o que alteraria a lógica do consumo dali por diante. Os Baby Boomers não somente alterariam o cenário mercadológico, por absorver os produtos produzidos em larga escala para as novas massas que formavam, tornando possível o escoamento da produção industrial por eles demandada, mas modificariam também a forma com que era pensado o desenvolvimento etário. Isso porque, pela primeira vez na formação social, uma geração clamaria para si o estado da juventude, inserida de maneira inédita entre a infância e a fase adulta. Eram os novos jovens, que talhariam as revoluções por vir, tais como o movimento gay, o movimento feminista, os protestos pelos direitos civis e tantos outros, que mudariam a história. Esse crescimento populacional não ocorreu apenas nos Estados Unidos, estendendo-se pelo mundo e levando consigo os mesmos ares de mudança.

[...] a Era de Ouro foi um fenômeno mundial, embora a riqueza geral jamais chegasse à vista da maioria da população do mundo. [...] Entretanto, a população do Terceiro Mundo aumentou num ritmo espetacular - o 
número de africanos, leste-asiáticos e sul-asiáticos mais que duplicou nos 3 anos depois de 1950, o número de latino-americanos mais ainda [...] Durante as décadas douradas não houve fome endêmica, a não ser como produto de guerras e loucura política, como na China. Na verdade, à medida que a população se multiplicava, a expectativa de vida aumentava em média sete anos. (Hobsbawm, 2009, p. 255)

$\mathrm{Na}$ base dessas mudanças sociais em que se formaram os referenciais dos Boomers, temos o importante fator do desenvolvimento e estabelecimento das mídias como forma de transmissão de influências de um novo mundo sem fronteiras. A mídia impressa, com seus influentes jornais e revistas, já direcionava modelos comportamentais de diferentes públicos, produzia seus barões da imprensa no período pré-Segunda Grande Guerra e continuou ampliando seu poder. Os mesmos periódicos vendiam mais que mercadorias em suas páginas, com anúncios publicitários de tabaco, xampus e sabões em pó. Vendiam também um novo comportamento, com seus modelos representados nesses mesmos anúncios e também nas chamadas "histórias", carregadas de sedutores referenciais do mundo moderno, a serem seguidos pela nova massa consumidora.

A mídia se desenvolveu para além das páginas impressas, e os Baby Boomers tiveram também influências vindas pelas ondas do rádio, que transmitia informações de maneira mais clara, diretamente para os lares das pessoas. A transmissão de influências passa a ser mais rápida e a alcançar maiores distâncias. Nos Estados Unidos, por exemplo, o rádio começa gradativamente a substituir os gramofones e a levar sua programação aos mais distantes pontos do país, apresentando novos estilos de vida adequados aos produtos que eram oferecidos aos ouvintes. O mesmo pode ser dito do cinema, capaz de mobilizar um contingente enorme de pessoas, a imagem cinematográfica, principalmente aquela produzida por Hollywood, ainda hoje, é responsável pela criação de mitos e influencia comportamentos e modas. Também a televisão, com seu surgimento, presente em milhões de lares pelo mundo, num curto espaço de tempo, vê-se avanços a passos largos dessa nova cadeia social. Formava-se uma nova lógica mundial, calcada pelo consumo e pelo acesso, antes restrito a poucos, de um universo luxuoso, agora possível para muitos, ainda que o fizessem como consumo das ideias e modelos.

Era a chegada da sonhada modernidade, vivida e constituída a partir do consumo em que se desenvolveram os Baby Boomers, os quais tiveram acesso a bens e experiências que as gerações anteriores jamais tiveram. Viram e participaram ativamente de todas essas mudanças. Descrevendo o comportamento dos Baby Boomers, Bauman (2011) menciona sua forte tendência a se agarrarem às oportunidades e se dedicarem ao trabalho duro com a finalidade de conseguir patamar de segurança e conforto suficientes para oferecer aos filhos a tranquilidade que não tiveram e o alcance ao mundo mercantilizado ao qual foram apresentados. Isso faz dessa geração um grupo acostumado a lutar por seus objetivos e a mudar aquilo que não consideram bom o bastante, sendo adaptáveis por terem visto e ajudado a promover grandes mudanças sociais e tendo absorvido as turbulências por elas geradas. Mas também faz dessas pessoas constantes perseguidores de segurança e permanência do bem-estar conquistado, uma vez que temem voltar ao estado conhecido e indesejado de desprovimento e dificuldades. 
Pode-se perceber que as regras sociais eram, de certa forma, mais respeitadas como limites de conduta por boa parte dos Boomers. No entanto, levando em consideração que esta também é a geração responsável por tantos movimentos de transformação comportamental que refizeram a maneira de se encarar tais regras sociais, como os movimentos feminista e gay, certa incoerência poderia ser encontrada em suas bases comportamentais. É comum, ainda assim, considerar-se os indivíduos da geração do Baby Boom como mais tradicionais no que diz respeito às escolhas de carreira e na busca pelo sucesso profissional, como indivíduos que conservam certo pragmatismo do tempo em que o trabalho árduo, muitas vezes em empregos estáveis, mas pouco prazerosos, eram vistos como única forma de sucesso profissional, como vemos no exemplo citado por Erickson (2011).

[...] os Boomers se precipitaram na força de trabalho com entusiasmo e empenho; jogaram segundo as regras estabelecidas e galgaram acirradamente a hierarquia empresarial. Pode ser que não tenham gostado, mas não demorou para que entrassem na linha. Eles tendem a gostar de sistemas meritocráticos e se valem tanto do dinheiro quanto da posição para medidas do grau de seu sucesso. Procederam com desembaraço e só recentemente passaram a suspender o passo por um período suficiente para se perguntar sobre o verdadeiro valor do prêmio. (Erickson, 2011, pp. 43-44)

A transição da Geração Baby Boomer para sua sucessora se daria por fatores de grandes mudanças no meio social, atribuídos diretamente ao novo estado de produção e consumo em que se encontrava a sociedade no auge da Era de Ouro, auge também da juventude Boomer. Com toda a agitação mercantil e produtivista, viriam efeitos colaterais imprevistos e indesejados, mas tão reais quanto a própria modernidade.

Mal se notava ainda um subproduto dessa extraordinária explosão, embora em retrospecto ele já parecesse ameaçador: a poluição e a deterioração ecológica. Durante a Era de Ouro, isso chamou pouca atenção [...] porque a ideologia de progresso dominante tinha certo que o crescente domínio da natureza pelo homem era a medida mesma do avanço da humanidade. [...] o velho lema do homem de negócios do século XIX, 'Onde tem lama, tem grana' (ou seja, poluição quer dizer dinheiro), ainda era convincente (Hobsbawm, 2009, p. 257)

No final da Era de Ouro, os efeitos colaterais da expansão industrial e da massificação do consumo se apresentavam como consequências desse novo modo de vida. E é nesse período, em meio a essas consequências que se marca o nascimento dos primeiros integrantes da geração seguinte aos Baby Boomers: a geração X.

[...] a chamada 'geração X', que hoje tem entre 28 e 45 anos, nasceu num mundo diferente, o mundo que foi construído com a ajuda de dedicação ao trabalho, longas jornadas, prudência, parcimônia e espírito de sacrifício de seus pais. Embora, em geral, seguissem a estratégia e filosofia de vida 
dos pais, fizeram isso com relutância -e maior impaciência, à medida que o mundo crescia em riqueza e promessas de uma vida mais segura, para ver e desfrutar as recompensas oferecidas pela existência de temperança, moderação e abnegação de seus pais e sobretudo deles próprios. A 'geração $\mathrm{X}$ ' preocupou-se menos que seus pais com o futuro, concentrando-se no 'aqui e agora': uma vida de prazeres ao alcance de suas mãos e de consumo imediato. (Bauman, 2011, p. 59)

Com essa descrição feita por Bauman (2011) podemos perceber o perfil da Geração X como uma geração individualista, autocentrada, a fim de desfrutar do conforto e das vantagens trazidas pela nova ordem da sociedade de consumo, já tão bem estabelecida, mas também concentrada em produzir seu próprio espaço, ainda que não com o mesmo espírito dos Boomers. Mesmo com algumas semelhanças, como descrito, a transição entre Boomers e Xers foi atribulada, conflituosa e cheia de arestas.

Ainda uma coisa que ninguém esperava, no final dos anos de 1960 e início de 1970, era que, na geração posterior, [...], os boomers se veriam eles mesmos na desconfortável posição uma vez ocupada por seus próprios anciões: sob assalto pela chegada de um novo grupo recém-chegado de pessoas jovens empunhando aquilo que encaram como os excesso e falhas daqueles que os precederam. (Craig \& Bennett, 1997, p. 2, tradução nossa) Os jovens da Geração X foram vistos por seus predecessores de maneira nada positiva. Nos anos 80 e 90, quando a Geração X chega a sua juventude mais ativa, indo em busca de seu lugar no mercado de trabalho e chegando às esferas políticas e sociais mais visíveis, o cenário já não era mais o mesmo da Era de Ouro e os referenciais já haviam passado por muitas mudanças, principalmente, no que tange ao consumo mundializado e suas consequências sociais.

Considerando isoladamente os problemas da economia mundial eram, com uma exceção, menos sérios. Mesmo entregue a si mesma, ela continuaria a crescer. [...] a economia devia entrar em outra era de próspera expansão antes do fim do milênio, embora isso pudesse ser por algum tempo dificultado pelos efeitos posteriores da desintegração do socialismo soviético, pelo colapso de partes do mundo na anarquia e na guerra, e talvez por uma dedicação excessiva ao livre comércio global, sobre o qual os economistas tendem a ser mais deslumbrados que os historiadores. Apesar disso, o espaço para expansão era enorme. A Era de Ouro, como vimos, foi basicamente o grande salto avante das 'economias de mercado desenvolvidas', talvez vinte países habitados por cerca de 600 milhões (1960). A globalização e a redistribuição da produção continuariam a trazer para a economia global o resto dos 6 bilhões de pessoas do mundo. Mesmo pessimistas congênitos tinham de admitir que era uma perspectiva encorajadora para os negócios. (Hobsbawm, 2009, p. 549)

Portanto, os desafios a serem enfrentados pela Geração X em sua juventude foram diferentes daqueles encontrados ao longo do caminho de seus predecessores, ainda que as atri- 
bulações políticas continuassem a existir, já não eram tão desestabilizadoras quanto antes e a mercantilização crescente continuava a se expandir. Num cenário onde o mercado consumidor era muito maior e mais diversificado, era de se esperar que as manifestações sociais também fossem distintas.

Os bens de consumo a serem oferecidos a essa nova parcela da população não poderiam ser os mesmos oferecidos aos mais velhos. As preferências, os desejos e possibilidades eram outros e as ofertas de bens de consumo se configuraram como propostas de Design para esse novo público que surgia.

Muitos exemplos de bens de consumo podem ser usados como novas propostas dedicadas a essa juventude, tanto em objetos já existentes, apenas com "roupagem" dedicada a esses jovens, quanto novas propostas que, provavelmente, não se encaixariam no comportamento dos Boomers. Um objeto com essas últimas características parece ter reunido as qualidades necessárias a um produto para atrair os olhares e o desejo dos Xers de forma singular, causando uma identificação profunda a ponto de se tornar um dos ícones da geração.

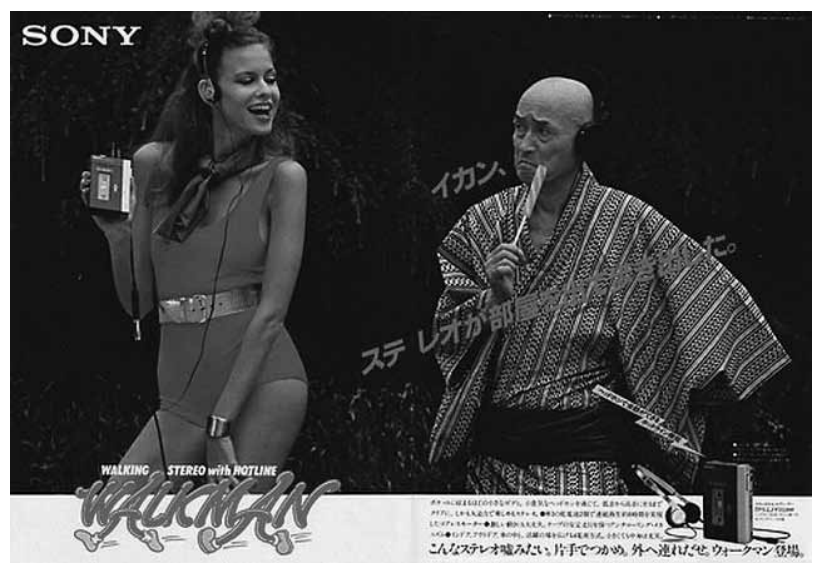

Figura 1. Sony Walkman AD. Fonte: http://mtjnm.wordpress.com

O walkman, marca registrada de um produto Sony que se tornou metonímia para todos os demais aparelhos de reprodução de áudio-portáteis a fita que o sucederam, foi criado, em 1979, no Japão, pelo designer então responsável pela divisão de áudio Nobutoshi Kihara, por idealização e demanda do sócio da corporação Akio Morita. Lançado no mercado internacional como uma aposta quase solo de Morita, o equipamento de reprodução de fitas K7 não inspirava confiança nem mesmo aos mais acostumados aos gadgets japoneses. Nenhum dos envolvidos, segundo relatos, nem mesmo o próprio Kihara, acreditavam no sucesso do produto, exceto seu entusiasta Morita (Nathan, 1999, p. 152).

O Projeto Walkman foi fundado na certeza e determinação de Morita; não houve processo de desenvolvimento convencional e nenhum teste de mer- 
cado. Desde o início Morita insistiu que o produto deveria ser acessível aos adolescentes. [...] Enquanto repórteres ficavam debaixo de árvores ouvindo um discurso gravado com música de fundo num aparelho de som, funcionários da Sony e modelos demonstravam como aproveitar o Walkman sobre patins, skates ou andando de bicicleta durante um encontro (Nathan, 1999, p. 152-153, tradução nossa).

O risco corrido por Morita resultou num sucesso sem precedentes na história do setor. Após seu lançamento, com um curto período de adaptação, o Walkman teve todas as unidades vendidas, produzidas em quantidade muito superior aos números normalmente operados pela Sony à época, para que os valores fossem os desejados por seu idealizador, sendo levadas das prateleiras de lojas em todo o mundo. A produção teve que ser dobrada e triplicada várias vezes nos anos seguintes. O Walkman havia se tornado a maneira de ouvir música dos jovens da Geração X. Nas próprias palavras de Morita: "A Sony criaria uma nova moda, uma cultura dos headphones" (Nathan, 1999, p. 154, tradução nossa). Divertir-se ou simplesmente flanar pelas grandes cidades em skates e patins escutando os seus ídolos musicais em fones de ouvido, claramente projetados para serem menores, mais leves e bem característicos, parece mesmo um retrato da Geração X em sua juventude. Música ouvida de forma particular, hedonista, individual, ao mesmo tempo em que se aproveitam as facilidades urbanas.

No mesmo período as mídias também passaram por mudanças importantes e que viriam a moldar de maneira ainda mais distinta o cenário mundial, exercendo forte influência principalmente sobre os jovens Xers. Em 1971, surgem os computadores pessoais, com o lançamento dos microprocessadores. Com funções ainda limitadas, em seu início, já tornavam bem mais simples tarefas como redação e impressão de textos e cálculos mais complexos. Já neste início essa nova tecnologia era vista como algo que revolucionaria o mundo e, por isso, carregava consigo ares de futuro, diretamente atrelados aos jovens e às novas gerações. Os computadores eram, então, encarados exclusivamente como ferramentas de trabalho, mas isso foi sendo alterado com o surgimento de programas e jogos destinados à diversão e lazer.

O que já ocorrera na transição entre as chamadas Gerações Tradicionais para os Baby Boomers ocorreria novamente. Novas tecnologias e cenários sociais, passando por alterações significativas pelo surgimento e difusão dessas novidades, gerariam comportamentos também alterados, por consequência. A exposição à inserção das novas tecnologias ocorridas nesse período fez da Geração X a que teve que se adaptar mais rapidamente a tantas mudanças, conferindo a esse grupo características mistas entre resquícios tradicionais, como forma de eco ainda das Gerações Tradicionais; também flexibilidade para adaptação rápida a um novo meio tecnológico, e, ainda, as referências familiares vindas de seus pais, os Boomers, que acreditam que o sucesso e a felicidade são fruto de muito trabalho e renúncias para a construção gradativa de uma vida plena.

Já na Geração X, a única geração na história a presenciar e se adaptar imediatamente ao processo de transição do mundo analógico para o digital, e deste para o virtual, a preocupação com o desenvolvimento do aspecto criativo 
do intelecto passou a ser maior, porém sem rejeitar totalmente a importância do desenvolvimento do aspecto repetitivo no processo de aprendizagem. $\mathrm{O}$ jovem da Geração X pode até priorizar o reconhecimento em sua área de atuação, mas ele sabe que tal reconhecimento será resultado de inúmeras renúncias pessoais, regras e privações, além de ser algo que poderá levar muitos anos para acontecer. Por outro lado trata-se de uma geração melhor preparada para compreender a necessidade de se investir tanto no aspecto criativo quanto no repetitivo da inteligência cognitiva. (Lima, 2012, p. 22-23)

Como dito anteriormente, a Geração X presenciou e se adaptou à transição do mundo analógico para o mundo digital, e, então, para o mundo virtual, logicamente, seguindo a difusão dos computadores pessoais em todo o mundo. Mas a solidificação da presença dos computadores pessoais nos lares veio a se confirmar pelos fatores relacionados à comunicação. Nos anos 90, surge a internet e populariza-se, a começar pelo uso dos emails, chats e salas de bate-papo, que revolucionam logo de início as comunicações. Esse é o marco da diversidade cultural possível em um mundo sem fronteiras, onde se concentram todas as possibilidades das mídias impressas, do cinema, do rádio e da televisão num só veículo, a internet, múltipla e diversa por natureza. Temos, então, a chamada "convergência", resultado da junção das mídias e dos computadores (Briggs \& Burke, 2004).

A partir disso apresenta-se a possibilidade da interação de maneira mais acentuada, interligando ainda mais as pessoas e também expandindo as possibilidades da mídia. Essa mesma "convergência" e todas as suas possibilidades apresentam seus efeitos secundários. Briggs e Burke (2004) comentam que o historiador Boorstin já alertava para duas facetas não tão fantásticas desse fenômeno. Uma delas é "a tendência de tudo se tornar igual a tudo" e a segunda é o fato de que "enquanto a comunicação era, em determinada época, um substituto inferior ao transporte, hoje, muitas vezes,é a alternativa preferida" (Briggs \& Burke, 2004, p. 270). Esses "efeitos colaterais" passam a ser uma realidade constante nas sociedades modernas, causando prejuízos culturais e promovendo o isolamento de indivíduos, mesmo dentro de grandes cidades repletas de pessoas. Passou-se a viver a configuração de fenômenos dúbios, com os quais temos que conviver, indesejados e contrários ao pensado para os meios de comunicação, que, em teoria, deveriam promover o contato e o convívio, a troca de experiências e as relações humanas.

Como fruto desse meio informacional já tão vasto, um mercado mundializado e regras sociais transformadas, os indivíduos da Geração X foram classificados de muitas formas distintas, sem tanto acordo entre diferentes autores. Mas algumas características foram descritas pela maior parte deles. Os Xers são vistos como egoístas, por viverem num contexto de consumo hedonista e pouco voltado para o bem comum; também como workaholics (viciados em trabalho) por encararem o campo profissional de maneira competitiva, o que pode ser tido como natural num mundo em que a oferta de trabalhadores, ainda que especializados, é grande o suficiente para que se possa substituir um profissional por outro com facilidade; como jovens adultos que adiam o casamento por serem os filhos do traumático divórcio; ainda como imediatistas que, por terem acesso fácil a bens de consumo antes relegado apenas aos mais ricos, dedicam-se a aproveitar em seu aqui e agora os benefícios do conforto de um mundo mercantil. 
Para fins de comparação entre as gerações citadas, os Boomers e os Xers, por uma visão mais popular e permeada por adjetivos, para tornar possível uma percepção de como esses grupos foram vistos socialmente em sua juventude, aqui estão alguns comentários publicados pela revista Time sobre ambos: "Os Boomers eram tudo, menos silenciosos... Eles exibiam muitas características, fizeram muitas declarações, sugeriram muitos quadros, frequentemente conflituosos -eles são bem educados, ricos, rebeldes, responsáveis, pragmáticos, idealistas, bravos, 'alienados' e esperançosos”. (Auer, 1967 apud Craig \& Bennett, 1997, p. 1, tradução nossa)

Anos depois, já quando tratando sobre os Xers, a mesma revista não foi tão elogiosa:

[...] indecisos, sem ambição e de poucos heróis, sem hinos, sem estilo para chamar de seu. Eles almejam entretenimento, mas sua capacidade de atenção é tão curta quanto um zap num controle de TV. Eles procrastinam o casamento porque temem o divórcio... Eles possuem apenas um vago senso de sua própria identidade, mas uma preocupação monumental com todos os problemas que a geração anterior vai deixar para eles consertarem. (Gross \& Scott, 1990 apud Craig \& Bennett, 1997, p. 2, tradução nossa)

Vendo essas descrições pode-se perceber que os Baby Boomers foram vistos em seu tempo de juventude como uma geração transformadora e preparada, ainda que conflituosa. Eram descritos na mídia com elogiosos atributos e ares quase heroicos. Já os Xers parecem ter sido rechaçados e tratados como uma geração que não tinha os atributos esperados para os sucessores dos jovens Boomers. Tidos como indecisos e sem referencial, com pouca atenção e preocupações banais.

Então o que dizer a respeito da geração posterior aos Xers? A mesma revista faz uma descrição dúbia, já contemporânea, da chamada Geração Y, também conhecida como Millennials:

Com a força de 80 milhões, eles são o maior grupo etário na história da América. Em cada país os millennials são diferentes, mas por causa da globalização, mídia social, a exportação da cultura ocidental e da velocidade das mudanças, os millennials em todo o mundo são mais similares uns aos outros que às gerações mais velhas dentro de suas nações. [...] Eles são a mais ameaçadora e excitante geração desde os Baby Boomers sobre revolução social, não porque eles estejam tentando tomar o 'poder', mas porque estão crescendo sem um. [...] A revolução da informação deu poder a indivíduos dando a eles tecnologia para competir contra organizações enormes: hackers VS. Corporações, bloggers VS. Jornais, terroristas VS. nações/estados, diretores de YouTube VS. Estúdios, programadores de aplicativos VS. indústrias inteiras. [...] Embora sejam arrogantes sobre seu lugar no mundo, os Millennials são também atrofiados, tendo prolongado um estágio da vida entre adolescência e fase adulta [...] Millennials estão interagindo o dia todo, mas quase totalmente por meio de telas. [...] Millennials aceitam melhor as diferenças, não apenas quanto aos gays, mulheres e minorias, mas com relação a todos. [...] Eles são sinceros e otimistas. [...] Seu mundo é tão plano que 
eles não têm líderes, o que é o motivo pelo qual revoluções da ocupação da Wall Street à Tahrir Square têm ainda menos chances que rebeliões anteriores. Eles querem aprovação constante. Eles têm um medo massivo de estar perdendo alguma coisa e têm uma sigla pra tudo. São obcecados por celebridades, mas não as idolatram respeitosamente a distância. Eles querem experiências, o que é mais importante para eles que bens materiais. [...] Eles são financeiramente responsáveis [...], mas isso não é tão difícil quando se está vivendo em casa e usando os cartões de crédito dos pais. Eles adoram seus telefones, mas odeiam falar neles. (Stein \& Sanburn, 2013, p. 26-27)

Nas descrições dos Baby Boomers e da Geração X feitas pela mesma revista em diferentes tempos podemos notar algumas características gerais apontadas para cada uma.

Quanto aos Boomers, a redação da Time parece tendenciosamente elogiosa, já com os Xers ela não foi tão benevolente. Ao tratar da Geração Y, vemos afirmações ambíguas e mais voltadas para uma contextualização que para definições isoladas. Resumidamente, a revista parece estabelecer uma leitura dos jovens contemporâneos como seres mais acentuadamente egoístas do que seus predecessores, mas também mais poderosos e influentes pelos meios de comunicação e tecnologias novas, aceitando-se melhor e se colocando de forma mais natural, por assim dizer, diante de um mundo transformado.

Levando em consideração o meio transformado pela abundância, em comparação aos cenários em que foram jovens as duas gerações anteriores, Bauman (2011) descreve os indivíduos da Geração Y como mais imediatistas e egoístas.

Os jovens da Geração Y nasceram num mundo que seus pais não conheceram na juventude, que lhes era difícil ou até impossível imaginar, quando tinham a idade que seus filhos têm hoje, e, que, depois, receberam com um misto de perplexidade e desconfiança: um mundo de emprego abundante, oportunidades aparentemente infinitas de prazer, cada um mais atraente que o outro e capaz de multiplicar esses prazeres cada vez mais sedutores, relegando as antigas satisfações a uma aposentadoria precoce e ao esquecimento final. (Bauman, 2011, p. 59-60)

Pode-se, portanto, perceber que o meio informacional e a evolução da lógica de mercado internacionalizado provocou alterações importantes no comportamento dos jovens da atualidade. Toda essa possibilidade de interação imediata com o mundo e oferta mais que abundante dos bens de consumo de todo tipo não poderia deixar de afetar o meio social, mais especificamente aqueles que nasceram e cresceram num mundo já com essa configuração. Outro demonstrativo desse fato é o próprio surgimento da Geração Y em ruptura com a Geração X, tão próximas em espaço de tempo, principalmente em comparação com a geração dos Baby Boomers, muito mais longa e subdividida.

Os meios de comunicação parecem ser fator decisivo também para os comportamentos da Geração Y. Enquanto os Xers viram o surgimento e estabelecimento da internet como algo inteiramente novo, curioso e convidativo, para a Geração Y ela é algo orgânico, naturalmente disponível, uma ferramenta que oferece muito mais que apenas facilidades de 
trabalho. É algo tão usual que sua falta parece ser estranhamente incomum e até inadmissível por longos períodos.

Em tempos não tão distantes, no passado, o acesso a tecnologias de comunicação era mais restrito que hoje. A oferta de alternativas de todas as faixas de preços, tanto dos serviços quanto dos objetos que possibilitam seu uso, é grande e a facilidade de crédito faz com que, mesmo os indivíduos menos abastados tenham a seu alcance todo tipo de aparato eletrônico com acesso à internet, como computadores de mesa, notebooks, tablets e telefones celulares que oferecem tantas funções às quais muitos usuários não conseguem valer-se de todas. Como os chamados smartphones, que preencheram as lojas e entraram na vida cotidiana de uma grande parcela da população mundial, sendo um dos objetos mais aclamados, principalmente, pelos jovens.

\section{There's iPhone. And then there's everything else.}

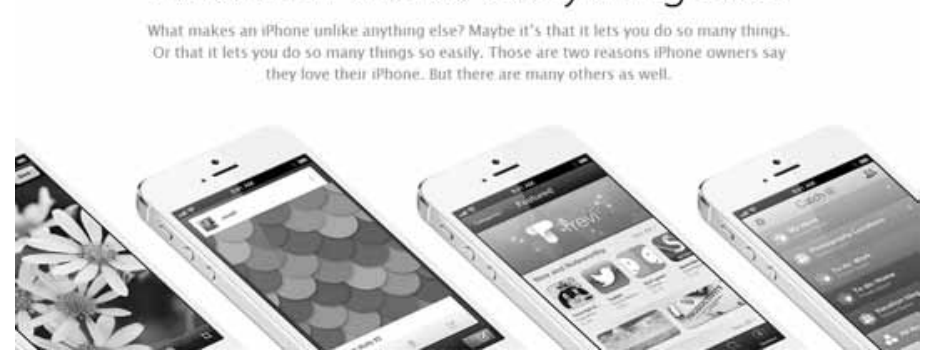

Figura 2. iPhone. Fonte: http://www.apple.com

O iPhone, smartphone criado pela norte-americana Apple Inc., é um exemplo de objeto que potencialmente expressa, como o Walkmen para a Geração X, características procuradas pelos indivíduos da Geração Y, em produtos. Esse smartphone, bem como todos os outros, permite acesso fácil à internet e tem programas (apps) de comunicação fácil com as redes sociais, pelas quais essas pessoas dividem seu dia a dia com amigos e estranhos. Mas ele tem outras características que, numa análise objetual, nos permitem vislumbrar, através da proposta de Design aqui envolvida, mais sobre as preferências dos Y.

Trata-se de um objeto conciso e "limpo", sem muitos botões ou peças externas, configurando-se, basicamente, como uma barra de vidro e alumínio lisos, adornados apenas por seu brilho e pela marca da cobiçada maçã. A princípio pode-se pensar que isso se deve ao fato de que se trata de um produto fabricado em altas escalas e distribuído para muitas partes do mundo, por isso não oferece muita "personalidade" ou características formais passíveis de dificuldades de absorção por fatores culturais em certas partes do mundo, mas a questão é que ele oferece múltiplas possibilidades de personalização.

As semelhanças entre o walkmen dos Xers e o iPhone são perceptíveis, guardadas as devidas diferenças de tecnologia envolvidas. O uso de fones de ouvido como símbolo, característica herdada do reprodutor de músicas iPod da mesma marca, e a possibilidade 
de uso durante outras atividades, pode demonstrar e confirmar as descrições dos autores sobre isolamento em meio a multidões e o hedonismo proposto por um bem de consumo que pretende conectar, mas que acaba por isolar cada pessoa em seu mundo particular de distâncias ambíguas.

\section{Considerações finais}

Ao tratar de uma proposta de design aceita o suficiente para ser considerada característica de uma juventude, faz-se necessário observar que essa posição lhe é atribuída por fatores que se somam às funções por ela realizadas e suas influências sobre os comportamentos dos jovens em questão. Essas influências, bem como toda proposta de design com tal poder de alcance por identificação, a transformam também em símbolo, passando a significar algo socialmente por si mesma, um referencial.

As características geracionais continuam, ao longo do tempo, a influenciar grandemente as escolhas e comportamentos dos indivíduos. As fontes de referência das pessoas não se deslocam de suas experiências na juventude a ponto de se reconfigurarem em abandono daquilo que lhes foi marcante em seu desenvolvimento. Continua-se a vivenciar e a perceber o mundo por meio dos referenciais estabelecidos e, como exposto nas construções anteriores, a juventude é a fase em que tais referenciais são construídos com maior ênfase.

Varias generaciones viven en el mismo tiempo cronológico. Pero como el único tiempo verdadero es el vivencial, se puede decir propiamente que todas viven en un tiempo interior que en lo cualitativo es plenamente diferente a los otros. Cada uno vive con gente de su edad y con gente de edades distintas en una plenitud de posibilidades contemporáneas. Para cada uno el mismo tiempo es un tiempo distinto; a saber: una época distinta y propia de él, que sólo comparte con sus coetáneos. (Mannheim Karl, 1928, p. 200)

Indivíduos das Geração Baby Boomer, X, Geração e Geração Y vivem, então, em tempos internos diferentes, embora dividam o tempo externo no mesmo cenário. Portanto, cabe ao design se atentar às características geracionais para compreender os fatores de influência sociais, contextuais e, também, objetuais dos indivíduos, se colocando a par das ramificações históricas, que culminam em comportamentos distintivos dentre cada grupo etário. Tal levantamento contextualizado também permite que se vislumbre o desenvolver de determinadas tendências comportamentais e escolhas de consumo dos distintos grupos de consumidores contemporâneos, atribuindo sentido às suas preferências e ligando-os a seus fatores de origem pelo contexto social e histórico em que se formaram.

\section{Referências}

Bauman, Z. (2011). 44 cartas do mundo líquido moderno. Rio de Janeiro: Jorge Zahar. Briggs, A.; Burke, P. (2004). Uma história social da mídia. Rio de Janeiro: Jorge Zahar. 
Craig, S.; Bennett, S. (1997). After the boom: The politics of generation X. Gainesville: Rowman \& Littlefield Publishers.

Erickson, T. (2011). E agora geração X? Como se manter no auge profissional e exercer a liderança plena numa época de intensa transformação. São Paulo: Elsevier.

Hobsbawm, E. (2012). Era dos extremos. São Paulo: Companhia das Letras.

Lima, R. (2012). Perfil das gerações no Brasil: as gerações X, Y e Z e seus perfis políticos. São Paulo: Baraúna.

Mannheim, K. (1993). "El problema de las generaciones", en REIS - Revista Española de Investigaciones Sociológicas (número. 62, pp. 193-242).

Nathan, J. (1999). Sonny. Santa Bárbara: Houghton Mifflin Harcourt.

Stein, J.; Sanburn, J. (2013). "Why millennials will save us all" en Time (v. 181, n. 19, pp. 26-33, May 2013).

Sudjic, D. (2010). A linguagem das coisas. Rio de Janeiro: Intrínseca.

Verganti, R. (2012). Design-driven innovation: mudando as regras da competição: a inovação radical do significado de produtos. São Paulo: Canal Certo.

Abstract: In attempt to comprehend the relations between consumer goods and behavior, as well as the action of design in this complex construct, it is necessary to perceive the context in which they happen and what are the influences and behavior tendencies in action inside this field, once it is natural to think that these factors are constantly transforming and adapting to the changes occurred along time.

The present paper is dedicated to the study of relations between the idea of youth and references, as well as contemporary design proposals that are mirroring important alterations in the social environment. Those alterations cover as young adults as well as middle-age people and elders, generating distinct consumption behaviors for goods and experiences based on generation distinction.

Keywords: design proposals - youth - value - consumption - time.

Resumo: No intento de compreender as relações entre bens de consumo e comportamento, assim como a atuação do design nesse complexo construto, faz-se necessário perceber o contexto em que elas acontecem e quais são as influências e tendências comportamentais em ação dentro desse campo, uma vez que é natural pensarmos que esses fatores se transformam constantemente, adaptando-se às mudanças ocorridas ao longo do tempo. O presente trabalho é dedicado ao estudo das relações entre a idéia de juventude e referenciais, também propostas de design na contemporaneidade, que vêm espelhando alterações importantes no meio social. Tais alterações abarcam tanto jovens adultos quanto pessoas de meia idade e idosos, gerando comportamentos de consumo de bens e experiências pautados pelas gerações.

Palavras chave: propostas de design - juventude - valor - consumo - tempo. 